\title{
The Applications of NPV in Different Types of Markets
}

\author{
Simin $\mathrm{Le}^{1, *}$ \\ ${ }^{1}$ University of California Santa Barbara, 93106, CA, United States \\ "Corresponding author. Email: siminle@ucsb.edu
}

\begin{abstract}
The net present value of your project is the present value of the cash flows at the required rate of return compared to your initial investment. In practice, it is a method of calculating the return on investment for a project or expenditure. This paper introduces some major methods to evaluate investment risk but focuses on the characteristics of the NPV method. The applications of the NPV method in different fields are also introduced. Using data from the provided example question, I developed models of change in the transformation curve in the complete and incomplete market. The advantages, disadvantages, and limitations of NPV are also be analyzed. Some recommendations for using the NPV method is presented.
\end{abstract}

Keywords: NPV, complete market, incomplete market, transformation curve, capital line

\section{INTRODUCTION}

Projects may sound appealing and beneficial, but it is difficult to determine if they fulfill their objectives without gathering data and performing an evaluation. Evaluation is necessary to ensure that limited resources are used effectively to have the largest potential impact. Monitoring and assessment are critical components of every project or program. Organizations use this procedure to gather and evaluate data to determine if a project or program has met its objectives. Monitoring begins immediately and continues throughout the length of the project. Following that, evaluation determines how well the program functioned.

The project assessment process is important to evaluate whether it is valuable to invest. At the most basic level of analysis, investors would want to ensure that the value of a large project outweighs the entire expenses. There are several methods for calculating the costs and benefits of a project for your organization. The four most frequent approaches are as follows.

\subsection{The payback periods}

The payback period is the length of time it will take to recover the original net investment in a project in the form of net cash inflows. This is a typical way to assess the risk of an investment. Shorter payback periods are typically seen as less hazardous investments. This technique does not consider other considerations, such as the time value of money and net cash flows after the initial investment is recovered.

\subsection{The accounting rate of return (ARR)}

The accounting rate of return (ARR) determines a project's return by dividing the yearly net revenue by the initial investment in the project. Assume you want to spend $\$ 1$ million on a piece of equipment. If the equipment generates $\$ 90,000$ in yearly net revenue, the project has an ARR of 9\%. When comparing projects, greater ARR investments will be more appealing. Although the simplicity of ARR makes it a popular ratio for project evaluation, it also leaves out a few crucial elements. ARR does not account for the time value of money, which states that a dollar today is worth more than a dollar in five years (since today's money may be invested to produce a return). ARR also does not consider cash flows, which are an important component of every investment project.

\subsection{The net present value (NPV)}

According to Magni [1], The Net Present Value maximizing model has a distinguished pedigree and is widely regarded as a theoretically sound decision model by most academics. The net present value (NPV) approach determines a project's projected net monetary gain or loss by bringing all expected future cash inflows and outflows to the present. Zizlavsky [2] explains the 
principles of NPV as a risky Euro tomorrow will be worth less than a certain Euro today. Although the precise worth of the project cannot be determined until it is completed, the NPV helps entrepreneurs to account for the time value of money when evaluating long-term initiatives.

\subsection{The internal rate of return (IRR)}

Simply defined, the internal rate of return (IRR) calculates a project's average yearly rate of return during its lifespan. The IRR, like the NPV, is a discounted cash flow analysis, which means it considers the declining value of money over time. The greater a project's predicted IRR, the more desirable it will be using this technique. While the IRR offers the investment's rate of return, the NPV provides the monetary amount that the investment would yield at the time of purchase. IRR is frequently used in conjunction with NPV. This is because, depending on the initial investment outflows and future net inflows, a project may have a low IRR yet a high NPV. This would imply that the project's rate of return may be lower than planned, but its contribution to the company's total worth is significant. IRR will also tend to favor shorter initiatives while undervaluing ventures that repay their worth over time.

Based on Ross [3], no student may graduate from the basic finance course without understanding the net-present-value rule. It is the substance of most textbooks and is central to what financial academics believe they can give CFOs, corporate treasurers, investment bankers, and practitioners of all sorts.

The literature for NPV is wide. Kumar et al. [4] investigate the impact of various factors affecting coal-fired power plant economics in north India for electricity generation based on the NPV method. The effort aims to produce a successful capital investment in north India's $210 \mathrm{MW}$ coal-fired thermal power plant. As a result, balanced integration of the coal-fired power plant cost analysis module and economics is required so that the power plant economic indices of the coal-fired power plant in terms of total capital investment, operating cost (i.e., fuel cost, operations and maintenance cost), revenue, and net present value can be analyzed. Most design decisions are based on economic considerations; consequently, economic considerations play an important role since the economics of coal-fired power plants are strongly related to technical elements. Tiong and Alum [5] focus on evaluating tender proposals for the build, operate, and transfer (BOT) projects, particularly in the Asia-Pacific region. It also uses the NPV method to provide an overview of current selection practices and techniques.
The net present value approach is distinguished because it is based on the premise that money received in the future is worth less than dollars in the bank today. Future cash flow is discounted back to the present to determine its value. The NPV technique generates a monetary value that reflects how much value the project will provide to the firm. Stockholders can plainly understand how much a project will add to their value.

However, the main issue with utilizing the NPV is that it entails making educated guesses about future cash flows and calculating a company's cost of capital. When comparing projects with varying investment levels, the NPV approach is inapplicable. A larger project that requires more money should have a greater NPV, but that doesn't mean it's a better investment than a smaller project. A firm frequently considers other qualitative variables. When comparing projects with various life lengths, the NPV method is challenging to use. How do you compare a project with positive cash flows for the next five years to one for the next twenty years?

In this paper, I will conduct the applications of NPV in complete and incomplete markets, examine the advantages and disadvantages of NPV, and show the limitations of NPV. The remainder of this paper is organized as follows: Section 2 analyzed how NPV is used in different types of capital market and then show the comparison; Section 3 describes the advantage of adopting the NPV method; Section 4 discusses the disadvantages and limitations of NPV. The last section presents my conclusions.

\section{MAIN BODY}

This section will present the application of NPV in both complete market and incomplete market by using an example question. The comparison of them will be shown through graphs of transformation curves. I will analyse based on the change from an old transformation curve to a new capital market line.

\subsection{NPV in the complete and perfect market}

Let's consider with an initial endowment of 500 in $\mathrm{t}=0$, and an investor can invest in the following nonmutually-exclusive and divisible investment projects.

Table 1. Cashflows for three investment projects

\begin{tabular}{lll}
\hline & Cashflow at $\mathrm{t}=0$ & Cashflow at $\mathrm{t}=1$ \\
\hline IP1 & -280 & 290 \\
IP2 & -80 & 120 \\
IP3 & -130 & 150
\end{tabular}

Assume for now that there is no capital market, then the return of each project can be calculated: 
Return of IP1: $(290-280) / 280=3.57 \%$

Return of IP2: $(120-80) / 80=50 \%$

Return of IP3: $(150-130) / 130=15.38 \%$

We summarize the result in Figure 2.

Table 2. projects return in the descending order of returns:

\begin{tabular}{llll}
\hline Project & CF0 & CF1 & Return \\
\hline 2 & -80 & 120 & $50 \%$ \\
3 & -130 & 150 & $15.39 \%$ \\
1 & -280 & 290 & $3.57 \%$ \\
\hline
\end{tabular}

We can draw a transformation curve based on the above data.

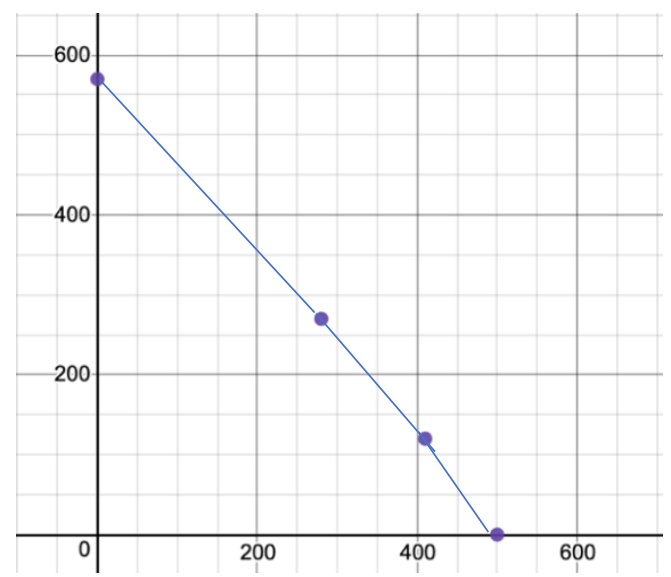

Figure 1. Transformation curve with no capital market

In this case, the Investor cannot borrow and lend money at the same rate. The optimal investment program is not independent of the consumption preferences of the investors. People would pick a project based on their risk preferences. For example, people who love risk and are very patient will pick a point on project 1 . People who hate risk and are impatient will choose a point on project 2 .

Now Assume that there is a perfect and complete capital market and that investors can invest and borrow money at a unique interest rate of $10 \%$. First, we need to know what a perfect and complete capital market is. A perfect market means that every asset or cash flow price is equal for all market participants. Thus, the assets are in total efficiency. And there is no arbitrage in a perfect market, which means that the process of simultaneously buying and selling a security at 2 different prices in 2 different markets cannot happen. Arbitrage would result in profit out of the price difference. And a complete market means that the information in every cash flow is symmetric between buyer and seller, and there is no transaction costs or tax fee in between. So basically, in this perfect competition and complete market, the financial transactions are zero net present value activity that will not add or subtract value in cash flow. To draw a new transformation curve with an interest rate of 10 per cent, we need to calculate the net present value.

$N P V=\sum_{i=1}^{n} \frac{R_{i}}{(1+r)^{i}}-$ Initial Investment

where, $R_{i}$ means the estimated net cash flow for the $i^{t h}$ period; $r$ represents the required rate of return per period, and $n$ is the project's life in months, years etc.

Then we calculate the three projects' NPV in the following.

$$
\begin{aligned}
& \text { NPV } 1=290 /(1+10 \%)-280=-16.36 \\
& \text { NPV } 2=120 /(1+10 \%)-80=29.09 \\
& \text { NPV } 3=150 /(1+10 \%)-130=6.36
\end{aligned}
$$

Based on those numbers, we can make some observations. Firstly, the NPV rule suggests investing in projects 2 and 3 since 1 has a negative net present value. So only 2 and 3 would bring the best profit. Secondly, the total wealth increase would be the sum of NPV 2 and 3, which is 35.45 . And the maximum possible consumption in times 0 and 1 can be calculated by considering the initial endowment 500 and interest rate of 10 per cent.

$$
\begin{gathered}
C_{0} \text { intercept }=\text { Initial endowment }+N P V 2 \\
\quad+N P V 3=500+35.45 \\
=535.45
\end{gathered}
$$

$C_{1}$ intercept $=C_{0}^{\max } \times 1.1=535.45 \times 1.1$ $=588.995$

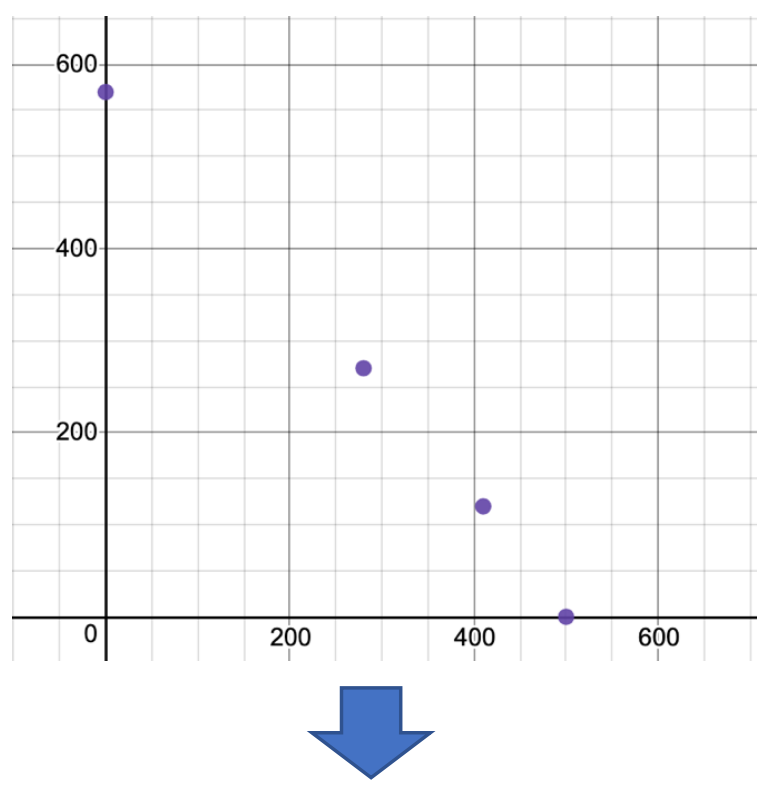




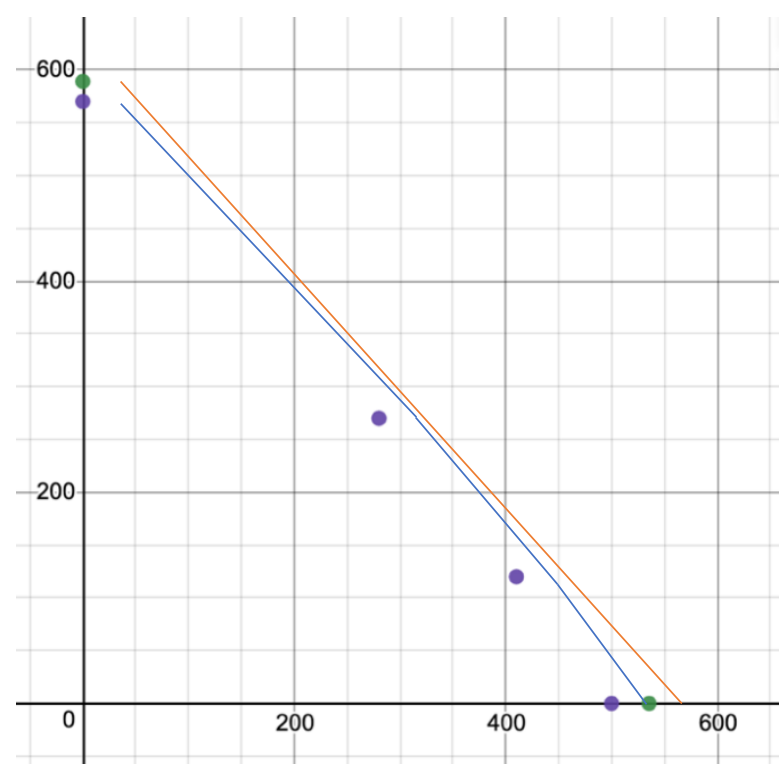

Figure 2. Comparison between old transformation curve and new capital market line

Now we can draw the new transformation curve with an interest rate of 10 per cent. On the old transformation curve, people would pick points based on their risk preference. But when there is a complete and perfect market with an interest rate of 10 per cent, people would prefer points on the new capital line since all points on this new line would provide a higher return than the old curve. Based on the graph, we can do some more analysis. First, the slope of this line would be negative 1.1 based on the interest rate. And the best investment plan which provides the highest return would be a combination of 2 and 3 since they offer positive net present value, as I mentioned before. From the graph, we can see that the new situation pushed the present value line as much as possible outwards, which is to the right, so it will maximize the level of possible consumption. Investment and consumption decisions are now separated because people always invest in the optimal investment that gives them the highest return. Based on the NPV rule, people's feasible market setup is increasing in the highest return. The new capital market line provides for a 10 per cent rate of change in consumption over time in both directions. In this case, when borrowing and investing rates are the same, the NPV rule can be used to make all investment choices.

\subsection{NPV in an incomplete market}

Use the same question above, but now consider an imperfect market with a deposit rate of $10 \%$ and borrowing rate of $20 \%$. We can now calculate two new interception points.

$$
C_{1}^{\max }=270+280 \times 1.1=578
$$

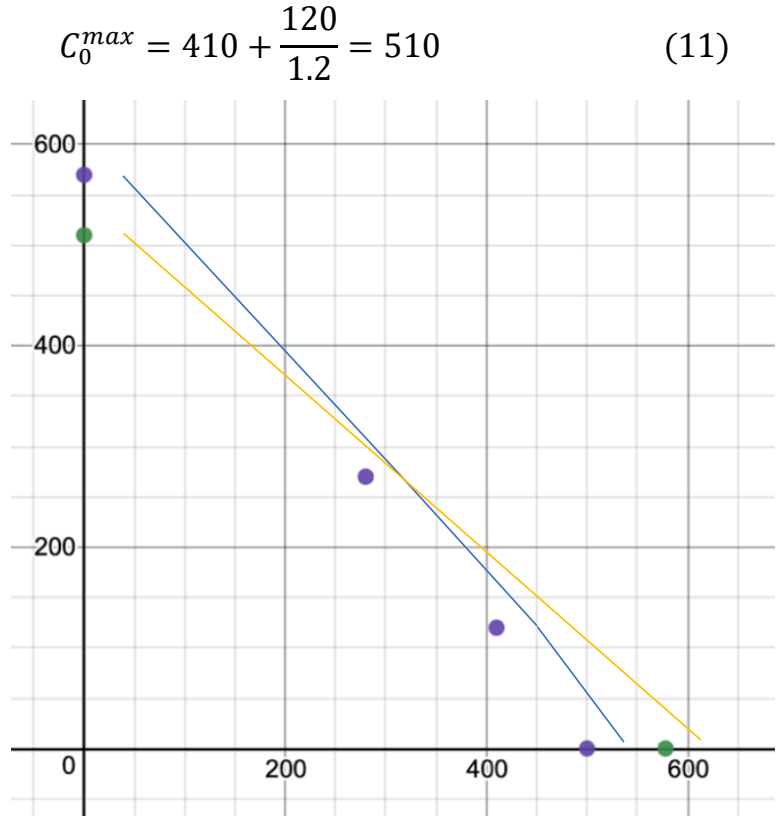

Figure 3. Imperfect market

Investment and consumption decisions are no longer unrelated. Impatient investors vote for Project 2 and then borrow money to achieve the optimal consumption point. Some more patient investors support Project 2 and a portion of Project 3. The most patient investors vote for projects 2, 3,1 and invest in the stock market. Conflicts among shareholders are unavoidable. However, some investors (in the outer segment) are better off than without a capital market.

\section{ADVANTAGE OF NPV}

(1) The net present value technique has the apparent advantage of considering the basic concept that a future dollar is worth less than a dollar today. The cash flows are discounted by another period of capital cost in each period.

(2) The NPV approach also tells us if an investment will generate value for the firm or the investor and how much value will be created in terms of dollars.

(3) Finally, the NPV approach considers the cost of capital as well as the risk associated with making future forecasts. In general, a cash flow prediction ten years in the future is less reliable than a cash flow projection next year. Cash flows predicted further in the future have less of an influence on the net present value than more predictable cash flows that occur earlier in the timeframe.

(4) For businesses, the NPV approach facilitates decision-making. It aids in the evaluation of similar-sized projects and aids in determining if a given investment is profitable or loss-making. Consider the following scenario-- A corporation want to spend $\$ 7500$ on a certain venture. The necessary rate of return is $10 \%$. The venture's expected inflows are as follows: 
Table 3. expected inflows for all projects

\begin{tabular}{ll}
\hline Y1 & 500 \\
\hline Y2 & 800 \\
Y3 & 2300 \\
Y4 & 2500 \\
Y5 & 3000
\end{tabular}

The project's NPV (as calculated using the formula) equals \$1995.9. The present value of cash outflows is greater than the current value of cash inflows in the given situation. As a result, it is not a feasible investment opportunity. (5) Another advantage of NPV is that it assists in maximizing the entity's earnings by investing in initiatives that give the highest returns.

\section{DISADVANTAGE AND LIMITATION OF NPV}

Firstly, the net present value method's main disadvantage is that it needs some guesswork regarding the firm's cost of capital. Assuming an unrealistically cheap cost of capital will lead to poor investment decisions. Assuming an excessively high cost of capital will result in the loss of too many excellent investments.

Secondly, the whole NPV calculation is based on discounting future cash flows to present value using the necessary rate of return. However, there are no rules for calculating this rate. This percentage figure is left to the company's discretion, and there may be cases when the NPV was incorrect owing to an incorrect rate of return. Another drawback of NPV is that it does not account for changes in the rate of return. A project's recovery quality is deemed steady, and any changes in the rate of returns necessitate a new NPV calculation.

Thirdly, NPV cannot be used to compare projects of varying sizes. The net present value (NPV) is an absolute amount, not a percentage. As a result, the NPV of larger projects will invariably be greater than that of smaller enterprises. The profits on the smaller project may outweigh the investment, but the overall NPV value may be lower. Because the NPV technique produces a monetary response, the amount of the net present value output is largely controlled by the input quantity. A \$2 million investment, for example, will almost certainly have a considerably greater NPV than a $\$ 2,000$ project, even if the $\$ 2,000$ project delivers far better returns in percentage terms. If money is scarce which it generally is - the NPV approach is a bad choice since projects of varying sizes are not directly comparable based on production. Let us better grasp this by using the following example: Project A needs a $\$ 250,000$ investment and has an NPV of $\$ 197,000$, but Project B requires a $\$ 50,000$ investment and has an NPV of $\$ 65,000$. Project $A$ is more profitable in absolute terms, but Project B offers a greater return on investment. As a result, NPV cannot be used to compare projects of varying sizes.

Finally, NPV solely considers the cash inflows and outflows of a certain project. It does not consider any hidden expenses, sunk costs, or any preparatory costs associated with the individual project. As a result, the project's profitability may not be extremely precise.

\section{RECOMMENDATION}

Ye and Tiong [6] demonstrate that a company's strategic capital investment decisions are critical. Investing in privately financed infrastructure projects necessitates careful consideration because they are subject to significant financial, political, and market risks. These risks should be analyzed as part of the project appraisal methods. Various capital-investment decision-making methods can consider risks, but each one focuses on different factors and has limitations. As a result, a more aggressive approach is required. Systematic classification of existing evaluation methods reveals that by combining the weighted average cost of capital and dual risk-return methods, a new method-the net-present-value-at-risk (NPV-at-risk) method-can be developed. The analysis of two hypothetical power projects demonstrates that the NPV-at-risk method can provide a better decision for risk assessment and investment in privately financed infrastructure projects.

Berkovitch and Isreal [7] show that net present value (NPV) as an investment criterion results in inefficient capital budgeting outcomes and how this criterion may be dominated by other capital budgeting criteria, such as the internal rate of return the profitability index. While firms use NPV to measure the addition to firm value from prospective projects, "classical" informational and agency considerations prevent them from implementing the optimal capital budgeting outcome. Their theory also identifies situations in which different criteria should be used rather than the NPV rule. Hanssen [8] mentions the E\&P business, characterized by large capital investments, extended payback times, and significant uncertainty for the most critical value drivers, such as market prices and reserve quantities. Major choices on asset purchases, drilling targets, concept selection, usage of new technology, risk-sharing agreements, and so on will significantly influence the value creation or value destruction of the company. Making decisions in the face of uncertainty is thus a critical problem in producing corporate value. The first aspect is that a decision model computes one or more decision variables, such as the net present value of a field development project. While this is obviously important for the choice, other considerations such as portfolio impacts of development, strategic relevance, and business risk appetite all impact the actual decision making. 
Pasqual et al. [9] conclude that net present value has long been regarded as the best criterion for project appraisal in academic circles; however, several alternatives, complementary methods remain popular with practitioners. Their paper shows that, when used correctly, several of these standard criteria, such as net final value, internal rate of return, benefit-cost ratio, profitability index, equivalent annuity, discounted payback period, and average payback period, lead to the same investment decision as net present value. Furthermore, they demonstrate that applying these criteria to the different projects yields the same ranking as net present value when deciding between two mutually exclusive projects. As a result, while net present value is regarded as a superior investment criterion, any of these popular criteria when properly applied, will suffice.

\section{CONCLUSION}

The difference between the present value of cash inflows and the present value of cash withdrawals overtime is defined as net present value (NPV). Net present value is a very common criterion in capital budgeting processes. Typically, uncertainty is handled using probability theory, and net cash flows are incorporated into the model as random variables. The net present value (NPV) is a calculation used in capital budgeting and investment planning to determine the profitability of a proposed investment or project. It is the outcome of computations used to determine the present value of a future stream of payments. It takes into consideration the time worth of money and may be used to evaluate similar investment options.

In this article, we find that the NPV is calculated using a discount rate determined from the cost of capital necessary to invest, and any project or investment with a negative NPV should be avoided. One significant disadvantage of NPV analysis is that it involves unreliable assumptions about future occurrences.

The writing of this paper and the system development process is also a process in which I have become more and more aware of my lack of knowledge and experience. Although I collect materials as much as possible and use what I have learned to do thesis writing and system development, there are still many shortcomings in the thesis. The system functions are not complete and need to be improved. The selected literature for this article is limited. The theoretical aspect is not yet systematically mature. It is still in the preliminary research stage, and the experimental program is not perfect. In addition, there are doubtful arguments in the thesis, which can be used as future research directions, such as how NPV can be combined with other methods to maximize profit.

\section{REFERENCES}

[1] Determining the value of a major project. BDC.ca. (2020, September

https://www.bdc.ca/en/articles-tools/money-financ e/manage-finances/financial-analysis.

[2] Magni, C. A. (2009). Investment decisions, net present value and bounded rationality. Quantitative Finance, 9(8), 967-979.

[3] Žižlavský, O. (2014). Net present value approach: method for economic assessment of innovation projects. Procedia-Social and Behavioral Sciences, 156, 506-512.

[4] Ross, S. A. (1995). Uses, abuses, and alternatives to the net-present-value rule. Financial management, 24(3), 96-102.

[5] Kumar, R., Sharma, A. K., \& Tewari, P. C. (2015). Cost analysis of a coal-fired power plant using the NPV method. Journal of Industrial Engineering International, 11(4), 495-504.

[6] Tiong, R. L., \& Alum, J. (1997). Evaluation of proposals for BOT projects. International journal of project management, 15(2), 67-72.

[7] Publisher The Motley Fool. (n.d.). Advantages and disadvantages of net present value method. Nasdaq. https://www.nasdaq.com/articles/advantages-and-d isadvantages-net-present-value-method-2015-11-1 4.

[8] Vaidya, A. byM. T. R. byD., Thakur, A. byM., by, A., Thakur, M., Vaidya, R. byD., by, R., Vaidya, D., \& Mpanza, N. (2021, July 29). Advantages and disadvantages of NPV. WallStreetMojo. https://www.wallstreetmojo.com/advantages-and-d isadvantages-of-npv/.

[9] Ye, S., \& Tiong, R. L. (2000). NPV-at-risk method in infrastructure project investment evaluation. Journal of construction engineering and management, 126(3), 227-233.

[10] Berkovitch, E., \& Israel, R. (2004). Why the NPV criterion does not maximize NPV. The Review of Financial Studies, 17(1), 239-255.

[11] Hanssen, T. H. (2006, June). How far can a state-of-the-art NPV model take you in decision making?. In SPE Europec/EAGE Annual Conference and Exhibition. OnePetro.

[12] Pasqual, J., Padilla, E., \& Jadotte, E. (2013). Equivalence of different profitability criteria with the net present value. International Journal of Production Economics, 142(1), 205-210. 